\title{
EFFECT OF CHESTNUT HYDROLYSABLE TANNIN ON WEIGHT MANAGEMENT AND OVARIAN HISTOPATHOLOGY OF HEALTHY FEMALE RATS
}

\author{
F. Manzoor ${ }^{1}$, M. N. Nisa ${ }^{* 1}$, H. A. Hussain ${ }^{2}$, N. Ahmad ${ }^{1}$ and H. Umbreen ${ }^{1}$ \\ ${ }^{1}$ Department of Food Science, Nutrition and Home Economics, Government College University, Faisalabad, \\ ${ }^{2}$ Department of Internal Medicine, Faisalabad Medical University, Faisalabad, 38000, Pakistan \\ *Corresponding Author's Email:Linknisa@gmail.com
}

\begin{abstract}
The hydrolysable Tannin (HT) is one of the phenolic compounds extracted from different vegetables and plants. The study was planned to evaluate the effect of HT on the weekly body weight gain, nutrient intake and ovarian histopathology of the healthy female rats. The 45 female rats $(135 \mathrm{~g} \pm 5 \mathrm{~g})$ were completely randomized into five groups i.e. HT0.5, HT1, HT1.5 and HT2 while HT0 was considered control group. The rats were offered different levels of HT $0.5,1,1.5$ and $2 \%$ in solution form through oral gavage method once in a day for six weeks. A significant decrease was observed $(P \leq 0.05)$ in weekly body weight, nutrient intake and weight gain of healthy female rats. No effect on water intake was observed $(P>0.05)$. The histopathology showed a well defined primary and secondary follicles, corpora lutea and graffian follicles. In conclusion the HT has shown negative effect on the nutrient intake but it has shown positive effect in reducing body weight of animals while no prominent histopathological changes and no signs of inflammation, follicular atresia or no detrimental effects were observed on the structural integrity of the ovaries of healthy female rats.
\end{abstract}

Keywords: Hydrolysable tannin, Body weight gain, Nutrient intake, Histopathology.

\section{INTRODUCTION}

Polyphenols are naturally present in many vegetables, fruits, legumes and beverages (Spencer et al., 2007). Among these phenolic, tannins are the most important oligomeric compounds. Being widely distributed among most of plant species, polyphenols have attracted much attention in recent years due to their multifunctional properties which are also beneficial for human health. The tannin can be well defined as a heterogeneous group of high molecular weight compound which forms complexes with carbohydrates, proteins and digestive enzymes, cellulose and some minerals (Butler, 1989; Bravo, 2009; Santos-Buelga and Scalbert, 2002). The tannin is divided into two major groups based on their molecular structure: Condensed tannin and HT. The commercially used HT extract is obtained from different woody plant sources like Chinese gall, Turkish gall, Sumac, Terminalia chebula and Sweet chestnuts (Castanea Sativa) (Bhat et al., 1998). The HT has high antioxidant activities (Wang et al., 1999). These natural antioxidants have received much attention and played an important role to combat the obesity (Hsu and yen, 2007).

The obesity or over weight is the condition of abnormal accumulation of lipids in adipose tissues leading to other metabolic disorders i.e. diabetes, cardiovascular diseases and infertility (Abu-Abid et al., 2002; Norman, 2010; Klop et al., 2013; Wang et al., 2014). The response of the body to insulin is impaired in obese patients which is called insulin resistance. The insulin is a hormone which plays a central role in ovarian functions including follicle development, granulose cell development etc, which can be impaired due to insulin resistance in over weight and obese patients (Norman, 2010; Shah et al., 2011; Sagae et al., 2012; Sohrabi et al., 2015). Oxidative stress (OS) is believed to be one of the major contributors of such effects in obese females. The OS has also adverse effect on folliculogenesis and oocyte development (Agarwal et al., 2012) due to improper functioning of the ovarian antioxidant system (Tilly and Tilly, 1995). The antioxidant system has great role in the prevention of acute toxic effects produced due to OS (Agarwal et al., 2005). The OS is the condition of production of the free radicals which results in the development of metabolic disorders. The HT decreases this state of OS by scavenging the free radicals (Frankic and Salobir, 2011; Andriyas and Lal, 2013). The HT is toxic to animals when used in large quantities and may lead to liver and kidney damage (Waghorn et al., 1994). Some toxic effects were observed on nutrient feed intake (Butler, 1989; Redondo et al., 2014), but another study reported that HT had also shown some positive effects on feed intake and animal performance (Schiavone et al., 2008 ), while 1.5 to $2.5 \%$ HT intake have shown no effect on DMI. The literature has showed the effect of HT for the treatment of obesity in obese animals. The positive or negative impacts of HT on ovarian health, body weight and nutrient intake in healthy condition are not yet investigated. Therefore, this study was designed to evaluate the impact of HT on the weight management and 
ovarian histological changes in healthy female albino rats.

\section{MATERIALS AND METHODS}

Forty five female albino rats of seven to eight weeks old with $135 \pm 5 \mathrm{~g}$ body weight were purchased from Riphah International University Lahore. They were kept in animal house of Department of Pharmacology, Government College University Faisalabad (GCUF). Standard guidelines of Animal Ethical Committee of GCUF for the management of the laboratory animals were followed which allowed for all the procedure conducted in the laboratory. The rats were kept at room temperature $25 \pm 2{ }^{\circ} \mathrm{C}$ with 45 to $55 \%$ humidity and 12 hour dark/light cycle. The duration of the trial was of six weeks. After seven days adjustment period, rats were divided into 5 groups with nine rats in each using completely randomized design. Identification marks were given to each rat by using permanent ink marker of different colors, which were applied to the tail of the rats (Silverman et al., 2014). The groups were named according to the HT dose levels i.e. HT0.5, HT1, HT1.5 and HT2 while HT0 was considered as the control.

Method of HT Solutions Preparation: The OECD'S guidelines were followed on volume selection using rats of different body weights. The required dose of HT for each rat was calculated by using following formula:

Dose $(\mathrm{mg}) / \mathrm{kg}$ rat $=$ Body weight of the rat $(\mathrm{g}) / 1000 \mathrm{~g} \times$ dose $(\mathrm{mg})$

The calculated levels of HT were dissolved in warm water to make their solutions (Oghenesuvwe et al., 2014; Bonelli et al., 2018) and offered to the rats once in a day through orogastric tube connected to a syringe (Elvis-Offiah et al., 2016).

Experimental Diet: The rats were fed ad libitum with iso-caloric and iso-nitrogenous diet as shown in Table 1. The standard diet contained the required vitamins and minerals as per AIN-93 guidelines (Yoshida et al., 2017; NRC, 1995). The composition of vitamin mix and mineral mix were used according to the formulation used by Ravees et al. (1993).

Sample Collection: The amount of water drank per experimental rat was measured daily by subtracting the left over water $(\mathrm{ml})$ from initial water (Laaksonen et al., 2013). The feed offered to each group was also weighed and recorded on daily basis to measure feed intake (Aguerre et al., 2016; Shi et al., 2015)

Proximate Analysis of Feed: Official Method of Analysis was used for the determination of dry matter, crude protein, crude fiber and crude ash and crude fat. The procedures are as follows: The samples of the diet in hot air oven were oven dried at $65 \mathrm{oC}$ for 48 . The dry matter (DM) contents were determined by applying following formula: $\% \mathrm{DM}=100-\%$ Moisture.

$\%$ Moisture $=$ Weight of sample $(\mathrm{g})-$ weight after drying $(\mathrm{g}) /$ weight of sample $(\mathrm{g}) \times 100$

Ash contents were determined by burning the samples at $550 \mathrm{oC}$ for four hours in a Muffle Furnace. The residue was inorganic matter and represented the total mineral contents. The petroleum ether extraction method was used for the determination of ether extract. The solvent ether removed lipid compounds. For the determination of crude fiber contents, the samples were boiled in $\mathrm{H} 2 \mathrm{SO} 4$ and then with $\mathrm{NaOH}$. The residue represented the less digestible carbohydrates mostly cellulose. Crude protein (CP) was determined by Kjeldahl method which measured the total nitrogen $(\mathrm{N})$. Then multiply the $\mathrm{N}$ with 6.25 (AOAC, 2000). The nitrogen free extract was calculated by difference i.e. $\% \mathrm{NFE}=$ 100 - $(\%$ moisture $+\%$ ether extract $+\%$ crude protein + $\%$ ash $+\%$ crude fiber) (Adenike, 2013).

Histological Examination of Ovarian Tissues of Healthy Female Rats: The rats were kept fast over night. Three replicates were made for each group. One rat was sacrificed from each replicate on next morning using chloroform anesthesia. For the histological evaluation, ovarian tissues were removed and cleaned from fatty tissues. The tissues were washed with normal saline and then put in $10 \%$ neutral buffer formalin for 48 hours before the preparation of slides. The ovarian tissues were processed through an automated tissue processor. The next step was embedded the samples in paraffin wax. The 5-micron thick part (slices) was taken and sliced using a microtome which was stained with Haematoxylin and Eosin (HandE) (Slaoui and Fiette, 2010). Stained horizontal sections were observed under microscope model number (XSZ107BN). The evaluation of the ovarian histological and pathological changes was confirmed by an Associate professor of Pathology, Allied Hospital Faisalabad.

Statistical Analysis: All the data were evaluated through ANOVA using IBM SPSS Statistics 21 (USA). Differences were considered significant at $P \leq 0.05$.

\section{RESULTS}

Weekly Body Weight and Body Weight Gain (g) of Healthy Female Rats: At the end of this six weeks trial, the effects of different levels of HT in different groups as H0.5, HT1, HT1.5 and HT2 on weekly body weight and body weight gain are presented in Figure 1 and 2. Weekly significant decrease $(P \leq 0.05)$ was observed in the body weight of all the tannin fed groups. The highest reduction in weight was noticed in rats of HT2 group. The weekly reduction $(P \leq 0.05)$ in body weight gain of all the groups was noticed which were fed with different levels of 
tannin. The highest decrease in weight gain was observed in the HT2 group.

Weekly Water Intake (ml) of Healthy Female Rats: The effect of different levels of HT on weekly water intake in different groups HT0.5, HT1, HT1.5 and HT2 are shown in Figure 3. No effect $(\mathrm{P}>0.05)$ was observed in any group.

Nutrient Intake (\%) of Healthy Female Rats: The weekly effect on nutrient intake of different levels of HT in different groups HT0.5, HT1, HT1.5 and HT2 are shown in Figures 4 to 8 . The weekly significant decrease $(\mathrm{P} \leq 0.05)$ was observed in dry matter intake by all groups with tannin intake as shown in Figure 4.The weekly effect of different levels of HT on crude fat intake in different groups as shown in Figure 5. The weekly significant decrease $(\mathrm{P} \leq 0.05)$ was observed in fat intake by all groups with tannin intake. The weekly effect of different levels of HT on crude protein intake in different groups is shown in Figure 6. Weekly significant decrease $(\mathrm{P} \leq 0.05)$ was observed in protein intake by all groups with tannin intake. The weekly effect of different levels of HT in crude fiber intake in different groups is shown in Figure 7. The weekly significant decrease $(\mathrm{P} \leq 0.05)$ was observed in fiber intake by all groups with tannin intake. The weekly effect of different levels of HT on ash intake in different groups is shown in Figure 8. The weekly significant decrease $(\mathrm{P} \leq 0.05)$ was observed in organic matter by all groups with tannin intake.

Histopathology of the Healthy Female Rats Ovaries: The ovarian histopathological study was conducted by following the procedure of Krause (2001). The histopathological observation of the ovaries of control group (HTO) revealed a well defined primary and secondary follicles, corpora lutea and graafian follicles as shown in Figure A while the rats treated with different levels of HT i.e. HT0.5, HT1, HT1.5 and HT2 also presented all the normal features of the ovaries like control group as shown in Figures B to E. No detrimental effects were observed.

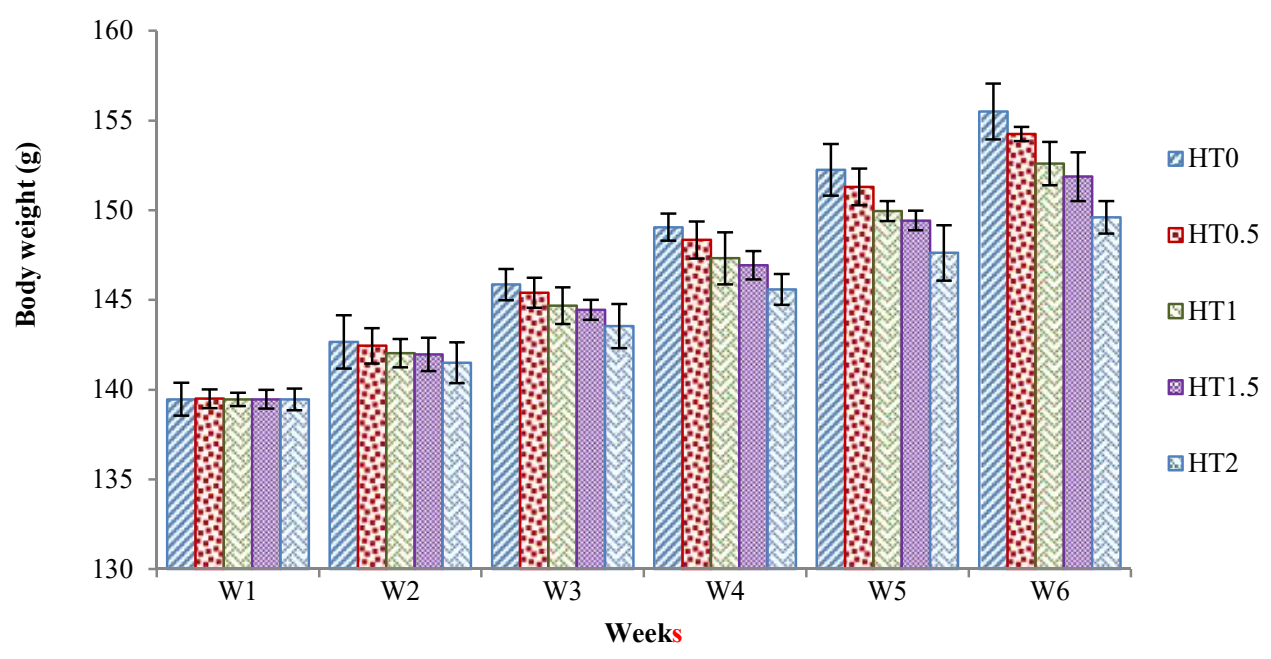

Figure 1: Weekly Body Weight of Healthy Female Rats

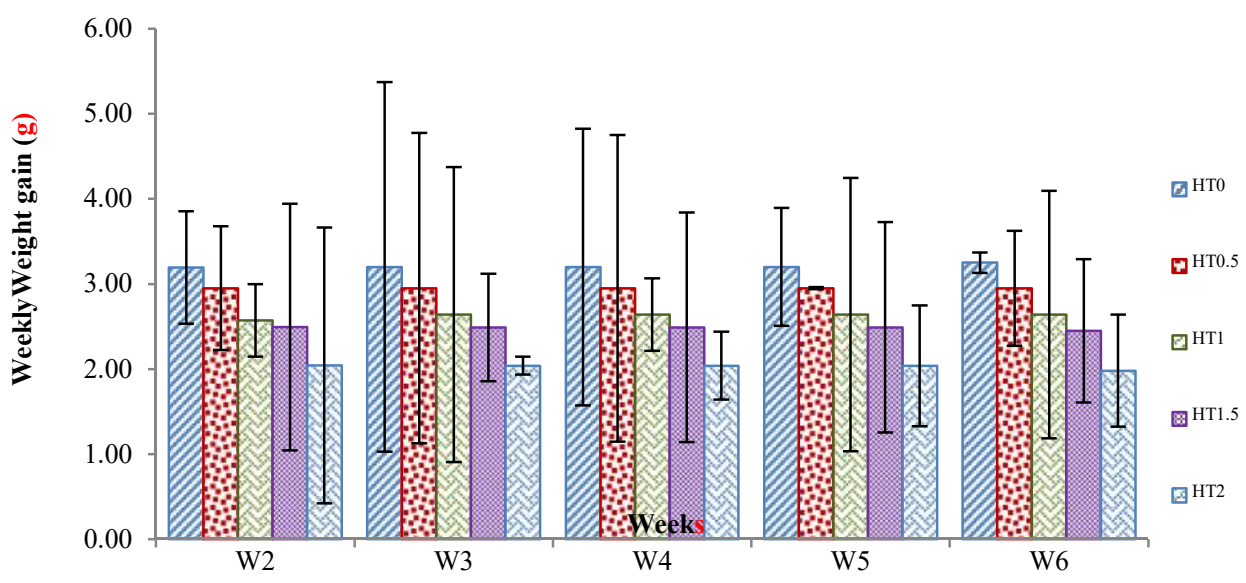

Figure 2: Weekly Body Weight Gain of Healthy Female Rats 


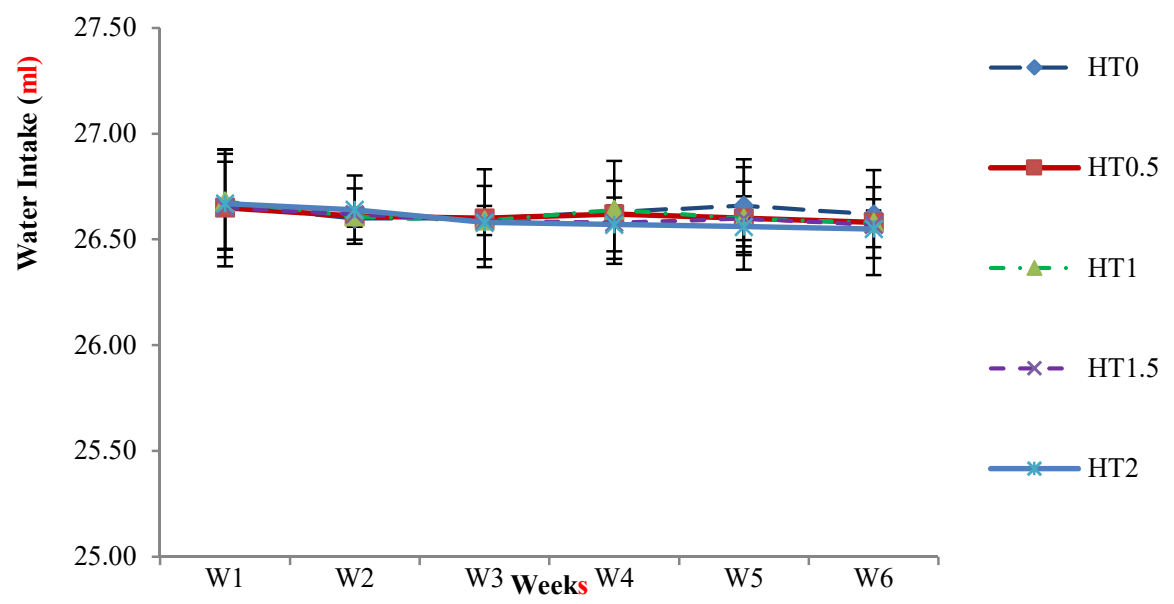

Figure 3: Weekly Water Intake of Healthy Female Rats

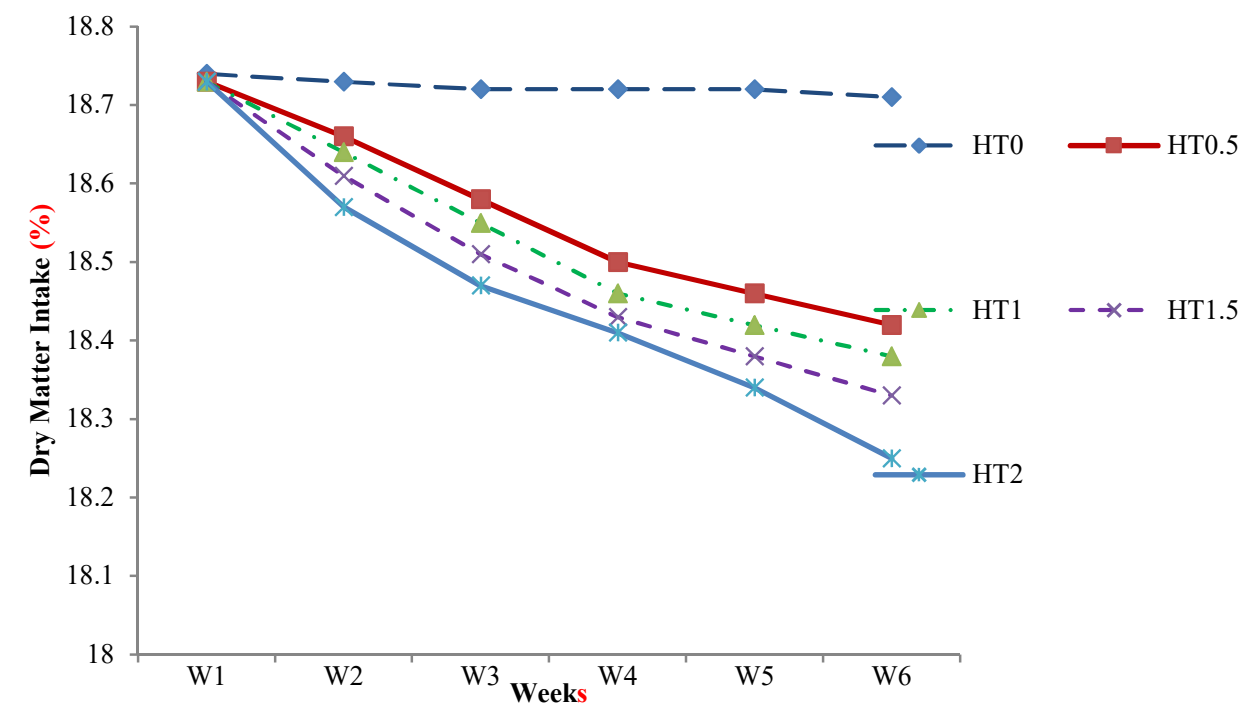

Figure 4: Weekly Dry Matter Intake of Healthy Female Rats

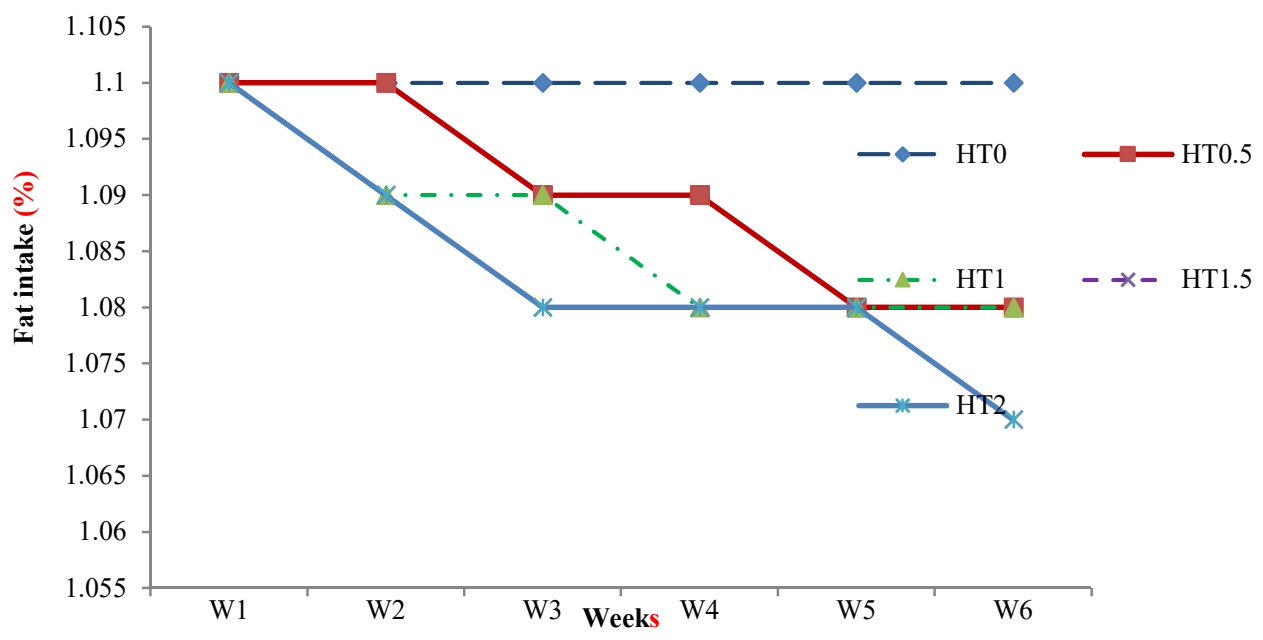

Figure 5: Weekly Fat Intake of Healthy Female Rats 


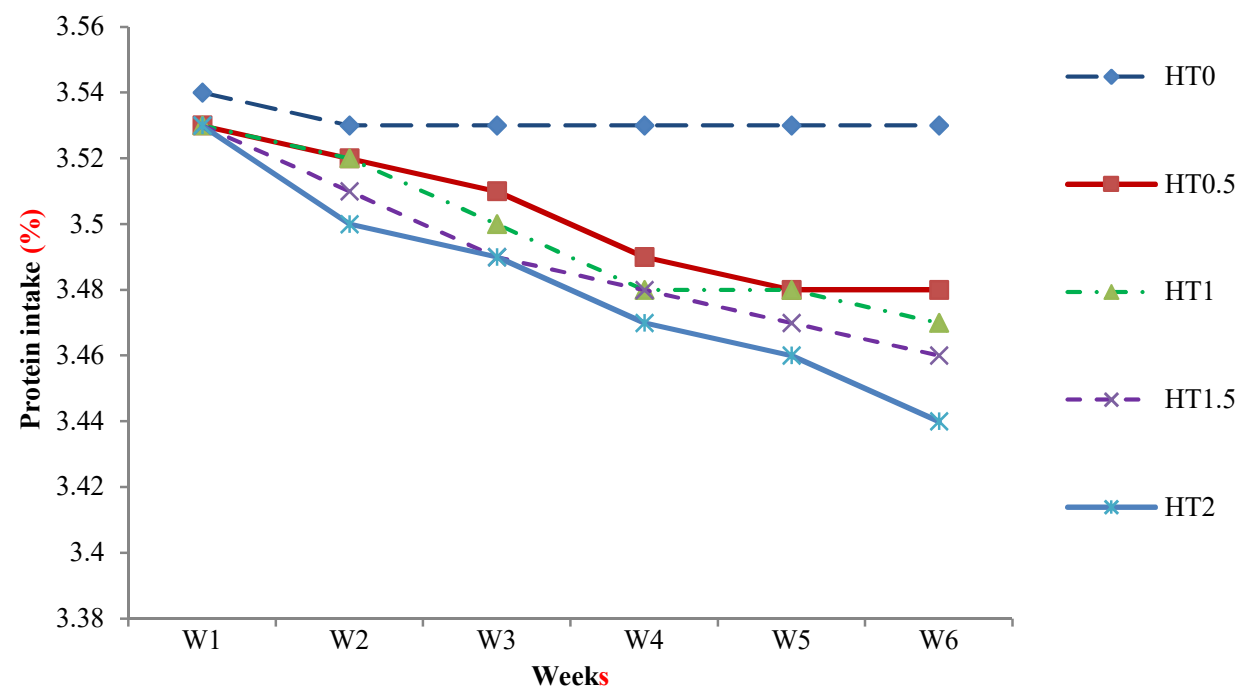

Figure 6: Weekly Protein Intake of Healthy Female Rats

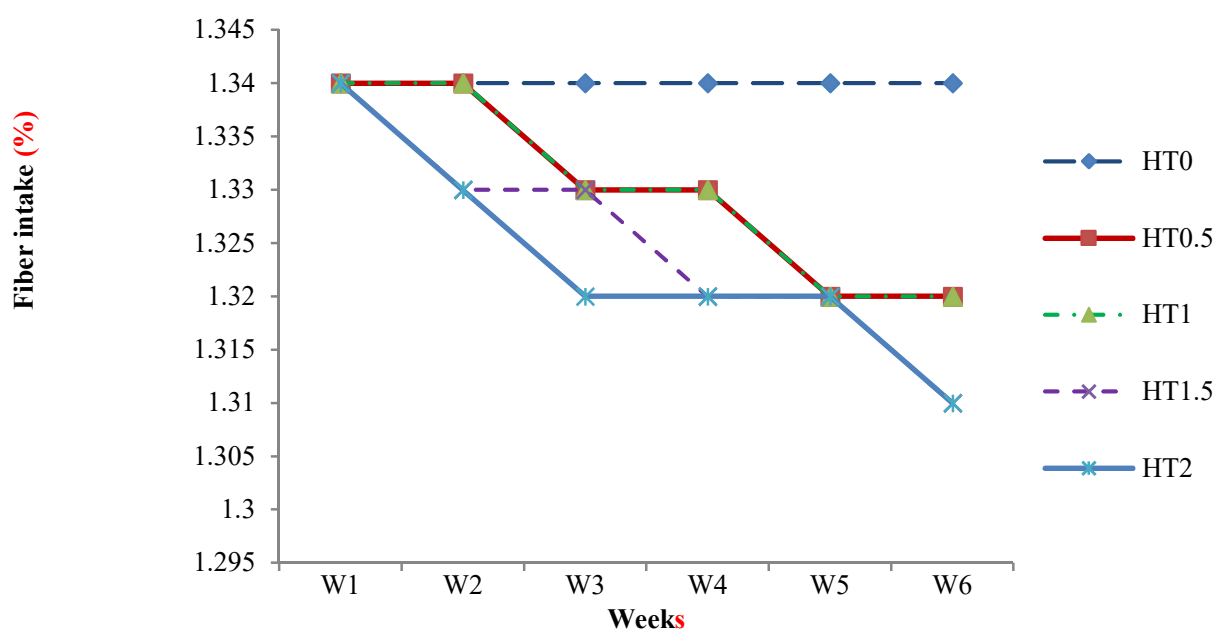

Figure 7: Weekly Fiber Intake of Healthy Female Rats

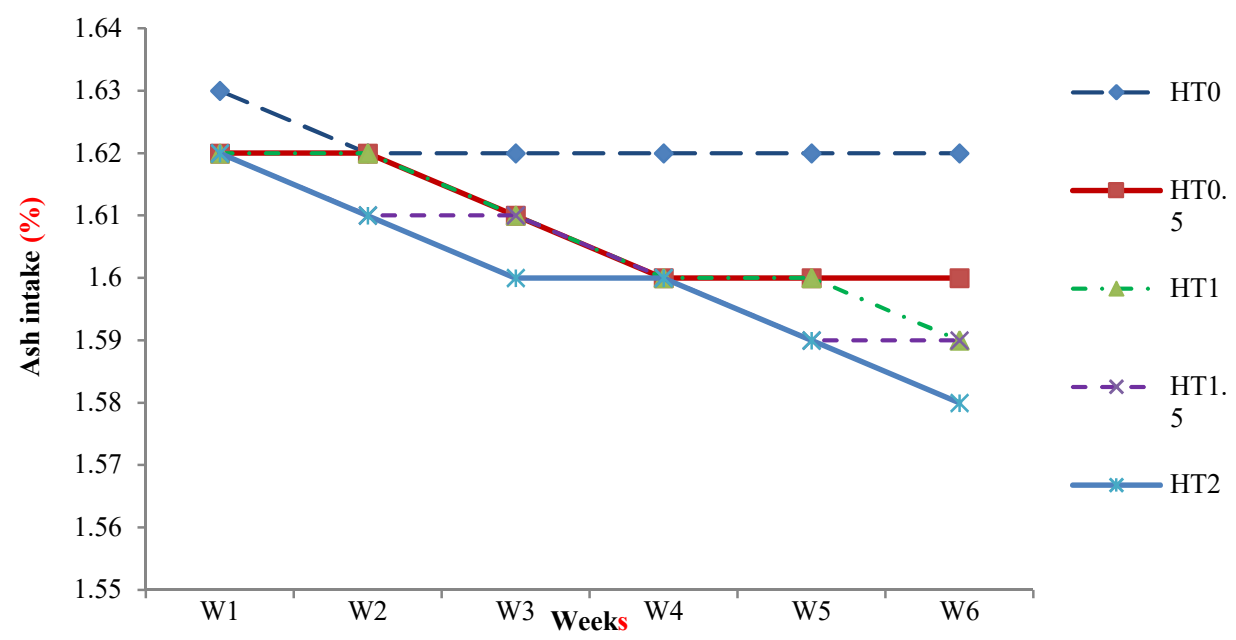

Figure 8: Weekly Ash Intake of Healthy Female Rats 


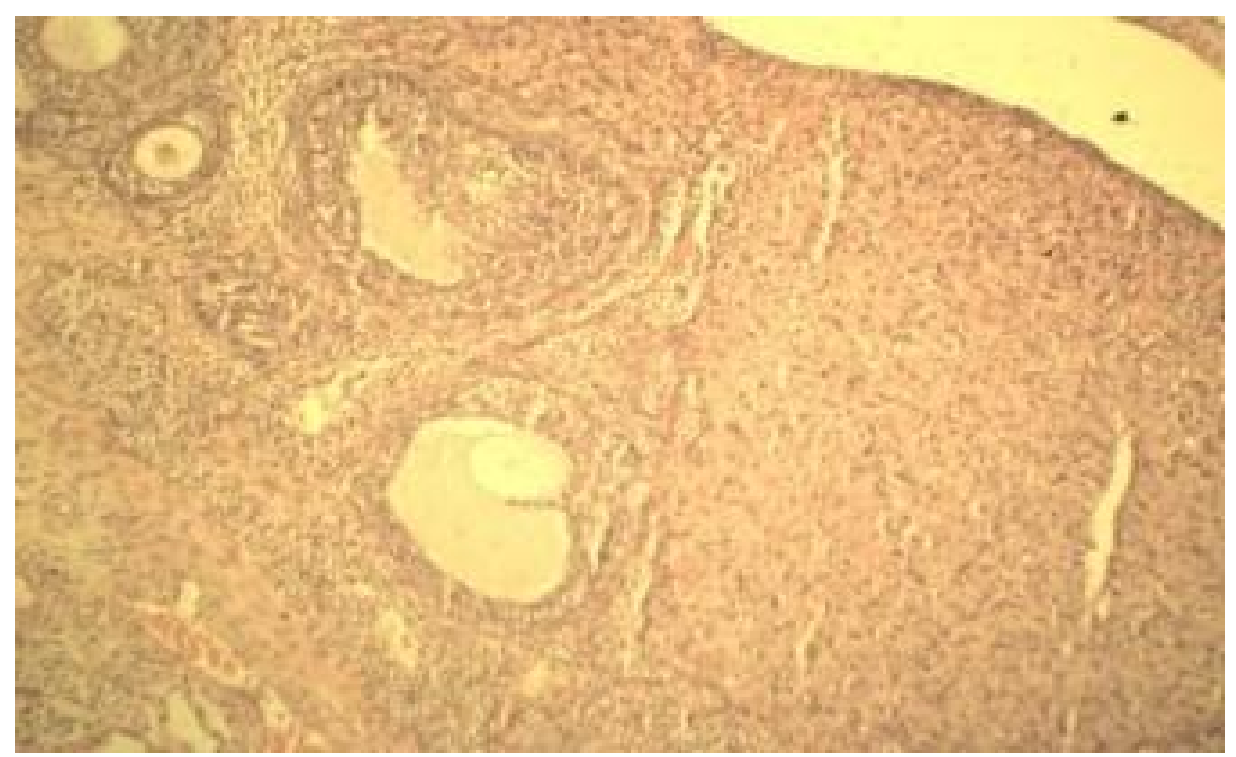

Figure A: (H and E; x 100) HT0

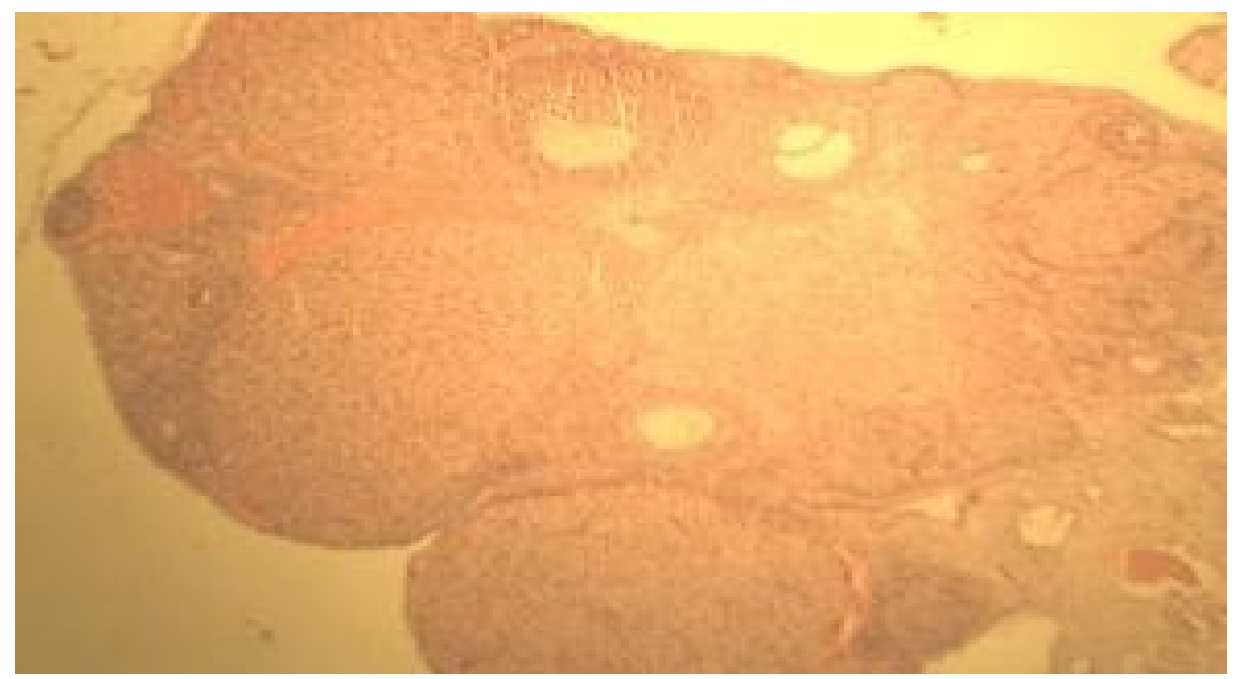

Figure B: (H and E; x 100) HT0.5

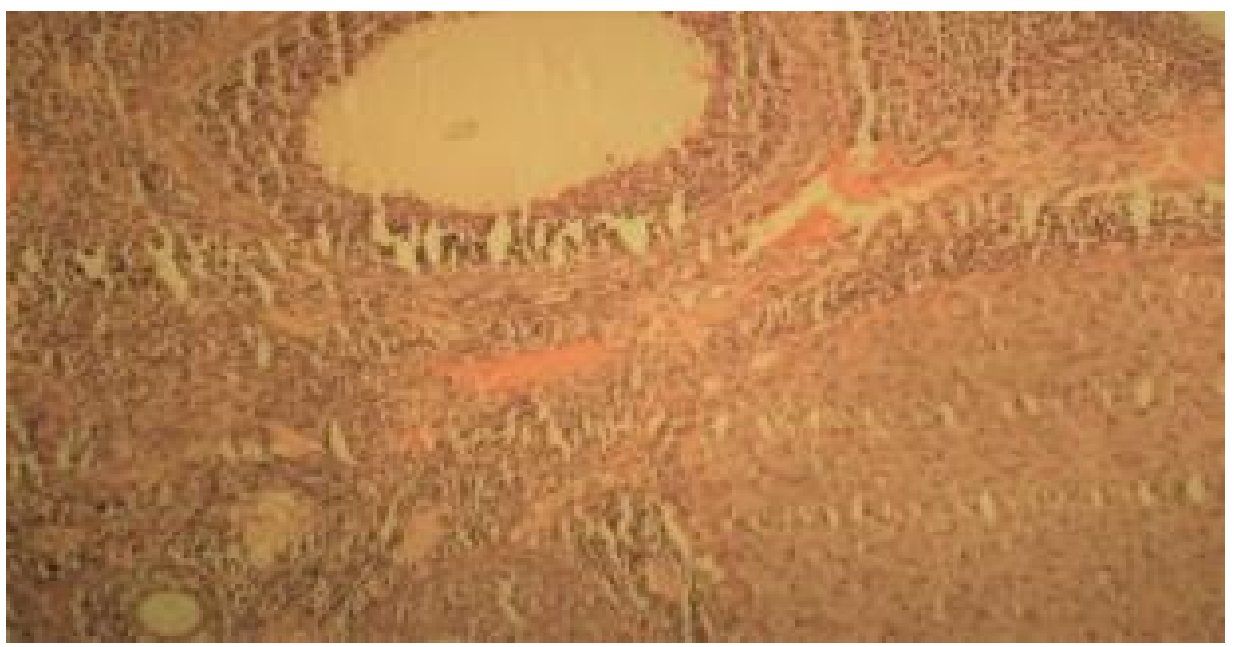

Figure C: (H and E; x 100) HT1 


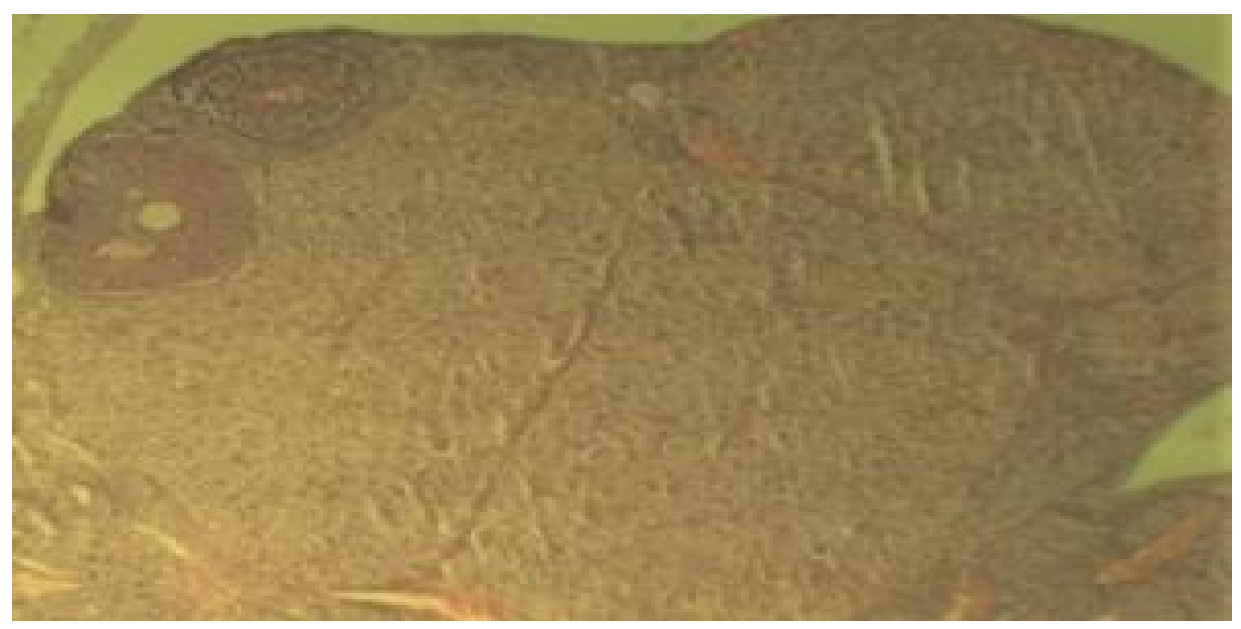

Figure D: (H and E; x 100) HT1.5

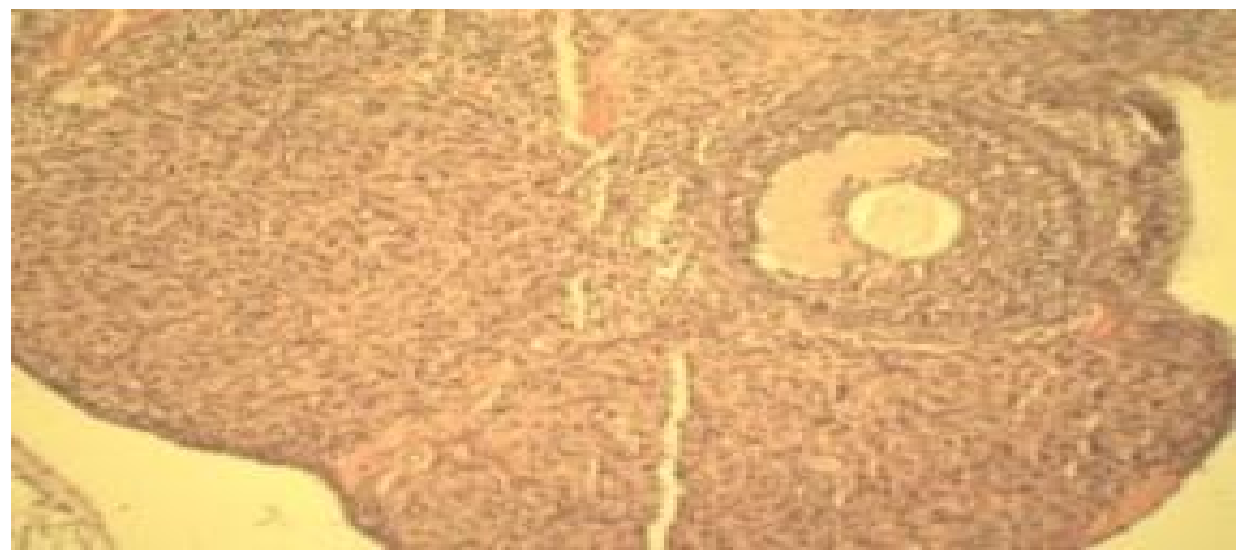

Figure E: (H and E; x 100) HT2

Table 1: Diet Composition (g/kg) and Nutrient level on Dry Matter Basis (\%)

\begin{tabular}{cc}
\hline Ingredients & Amount $\mathbf{( g / \mathbf { 1 0 0 0 }})$ \\
\hline Corn Starch & 230 \\
Maltodextrine & 100 \\
Sucrose & 100 \\
Soya Bean Meal & 420 \\
Maize Bran & 50 \\
Soyabean oil & 50 \\
Methionine & 3 \\
AIN 93G Vit Mix & 10 \\
AIN 93G Min Mix & 35 \\
Choline Bitartarate & 2 \\
Total Calories (Kcal) & 3.822 \\
Composition of Diet (g/kg) on Dry Matter Basis & $88.2 \%$ \\
Dry Matter & $11.8 \%$ \\
Moisture & $8.7 \%$ \\
Ash & $5.9 \%$ \\
Ether Extract & $7.2 \%$ \\
Crude Fiber & $18.9 \%$ \\
Crude Protein & $47.5 \%$ \\
\hline
\end{tabular}




\section{DISCUSSION}

Being naturally occurring phenolic compounds, HT possesses many biological activities including antiviral, anti-microbial, antioxidant and immune-modulator etc. (Huang et al., 2018). Nutrition is one of the most important contributing factors in the maintenance of health and reproduction of the living things. The hunger and satiety are two main factors that affect intake (Forbos, 1996). Food intake is a very complex behavior that helps to fulfill the biological energy requirement of the living beings (Berthoud, 2006). It has been reported that diet containing high levels of tannin decreased the intake and digestibility of nutrients (Frutos et al., 2004; Ekambaram et al., 2018).

According to Butler (1992), the 2\% intake of HT has significantly reduced the DMI which was consistent with the present work. The present data also showed that HT had decreased the intake of crude fat, crude protein and ash contents of the rats. The possible mechanism for the reduction in intake might be slowed down DM digestion which impaired the emptying of digestive tract. As a result, satiety signals were generated as a feed back to the nerves that were involved in intake control center of the rats and decreased the feed intake (Narjisse et al., 1995). It was previously reported that anti-nutritional property of the HT affected the weight gain of the animals. The tannin intake decreased the growth rate and weight gain of rats and reduced feed consumption (Chung et al., 1998; Nakamura et al., 2001). So the present study confirms the previous findings that HT has decreased the weight gain of rats. The mechanism behind diminish growth rate with tannin intake might possibly due to the systemic effects associated with tannin intake, because the inhibition of dietary material is less important than inhibition of the post digestive mechanism.

The diet supplemented with HT when fed to rats significantly reduced their body weights (Hsu and Yen, 2007). The present results also confirmed the Hsu and Yen (2007) findings that HT had significantly reduced the body weight of the rats. The reduction in body weight might be due to anti-nutritional property of HT, because HT formed complexes with macronutrients i.e. carbohydrates and protein which as a result decreased the digestibility of the food and resulted in weight loss (Butler, 1992). The other reason of decrease in body weight was due to insulin and leptin resistance because it had been reported that HT improved insulin and leptin resistance and thus decreased body weight (Hsu and Yen, 2007). The histological study revealed that HT had produced no sign of ovarian toxicity, inflammation, necrosis and follicular atresia or other damaging effects on the structural integrity of the ovaries of healthy female rats.
Conclusions: It is concluded that the chestnut HT has shown negative effects on the dry matter intake, crude protein, fat, fiber and ash intake but it helps to reduce the body weight of the rats. Therefore, it can be used to manage obesity and its related metabolic disorders. No prominent histopathological changes or other detrimental effects of HT were observed on the structural integrity of ovaries of healthy female rats. Hence, it is proved that different levels of HT i.e. $0.5,1,1.5$ and $2 \%$ are not detrimental to ovarian health.

\section{REFERENCES}

Abu-Abid, S., A. Szold and J. Klausner (2002). Obesity and Cancer. J. Med. 33:73-86.

Adenike, K. (2013). Effect of processing on the lectin and trypsin inhibitor content of Plukenetia conophora seeds as it affects growth performance and nutrients metabolism in rat. Afri. J. Food. Sci. 7(9): 306-316.

Agarwal, A., A. Aponte-Mellado, B. J. Premkumar, A. Shaman and S. Gupta (2012). The effects of oxidative stress on female reproduction: A review. Reprod. Biol. Endocrinol. 10: 1-31.

Agarwal, A., S. Gupta and R. K. Sharma (2005). Role of oxidative stress in female reproduction. Reprod. Biol. Endocrinol. 3:28

Aguerre, M., M. Capozzolo, P. Lencioni, C. Cabral and M. Wattiaux(2016). Effect of quebrachochestnut tannin extracts at 2 dietary crude protein levels on performance, rumen fermentation, and nitrogen partitioning in dairy cows. J. Dairy Sci. 99(6): 4476-4486.

Andriyas, E. A. and S. S. Lal (2013). Impact of Oxidative Stress on Reproductive Hormones in Fertile and Non-Fertile Females.

AOAC (2000). Official methods of analysis. Arligton, Virginia, USA: Association of Analytical Chemists. 17.

Berthoud, H. R. (2006). Homeostatic and nonhomeostatic pathways involved in the control of food intake and energy balance. Obesity. 14:197S-200S.

Bhat, T. K., B .Singh and O. P. Sharma (1998). Microbial degradation of tannins a current perspective. Biodegradation. 9(5):343-57.

Bonelli, F., L. Turini, G. Sarri, A. Serra, A. Buccioni and M. Mele (2018). Oral administration of chestnut tannins to reduce the duration of neonatal calf diarrhea. BMC. Vet. Res. 14(1).

Bravo, L. (2009). Polyphenols: Chemistry, Dietary Sources, Metabolism, and Nutritional Significance. Nutr. Rev. 56(11): 317-333.

Butler, L. G. (1989). Effects of Condensed Tannin on Animal Nutrition. Chemistry and Significance of Condensed Tannins. 391-402. 
Butler, L. G. (1992).Anti-nutritional Effects of Condensed and Hydrolyzable Tannins. Plant. Polyphenol, 693-698.

Chung, K.T., T. Y. Wong , I.W. Cheng, Y. W. Huang and Y. Lin (1998). Tannins and Human Health: A Review. Crit. Rev. Food. Sci. Nutr. 38(6): 421464.

Ekambaram, S. P., K. B. Babu, S. S. Perumal and D. Rajendran (2018).Repeated oral dose toxicity study on hydrolysable tannin rich fraction isolated from fruit pericarps of Terminalia chebula Retz in Wistar albino rats. Reg. Toxic. Pharma. 92: 182-188.

Elvis-Offiah, U. B., E. E. Bafor, G. I. Eze, O. Igbinumwen, C. Viegelmann and R. EdradaEbel (2016). In vivo investigation of female reproductive functions and parameters in nonpregnant mice models and mass spectrometric analysis of the methanol leaf extract ofEmilia Coccinea (Sims) G dons. Physiol. Rep. 4(23): e13047.

Forbes, J. M. (1996).Integration of regulatory signals controlling forage intake in ruminants. J. Ani. Sci. 74:3029-3035.

Frankic, T. and J. Salobir (2011). In vivo antioxidant potential of Sweet chestnut (Castanea sativa Mill.) wood extract in young growing pigs exposed to n-3 PUFA-induced oxidative stress. J. Sci. Food. Agri. 91(8): 1432-1439.

Frutos, P., G. Hervás, F. J. Giráldez and A. R. Mantecón (2004). Review: Tannins and ruminant nutrition. Span. J. Agri. Res. 2(2):191.

Hsu, C. and G. Yen (2007). Effect of gallic acid on high fat diet-induced dyslipidaemia, hepatosteatosis and oxidative stress in rats. Brit. J. Nutr. 98 (04).

Huang, Q., X. Liu, G. Zhao, T. Hu and Y. Wang (2018). Potential and challenges of tannins as an alternative to in-feed antibiotics for farm animal production. Anim. Nutr. 4(2):137-150.

Klop, B., J. Elte and M. Cabezas (2013). Dyslipidemia in obesity: Mechanisms and potential targets. Nutr. 5(4): 1218-1240.

Krause, W. (2001).The art of examining and interpreting histologic preparations: A student hand book. C.R.C. Press.

Laaksonen, K.S., T. O. Nevalainen, K. Haasio, I. H. E. Kasanen, P. A. Nieminen and H. M. Voipio (2013). Food and water intake, growth, and adiposity of Sprague-Dawley rats with diet board for 24 months Laboratory Animal. 47(4): 245-256

Nakamura, Y., A. Kaihara, K. Yoshii, Y. Tsumura, S. Ishimitsu and Y. Tonogai (2001). Effects of the Oral Administration of Green Tea Polyphenol and Tannic Acid on Serum and Hepatic Lipid
Contents and Fecal Steroid Excretion in Rats. J. Health. Sci. 47(2):107-117.

Narjisse, H., M. A. Elhonsali and J. D. Olsen (1995). Effects of oak (Quercus ilex) tannins on digestion and nitrogen balance in sheep and goats. Small Ruminant Res. 18 (3): 201-206

Norman, J. E. (2010). The adverse effects of obesity on reproduction. Reprod. 140(3): 343-345.

NRC. (1995). Nutrient Requirements of Laboratory Animals: Fourth Revised Edition (n.d.).

Oghenesuvwe., E.E. E. Nwoke and A. D. Lotanna (2014). Guidelines on dosage calculation and stock solution preparation in experimental animals' studies. J. Natur. Sci. Res. 4 (18):2224-3186.

Redondo, L. M., P. A . Chacana, J. E. Dominguez and M. E. Fernandez Miyakawa (2014). Perspectives in the use of tannins as alternative to antimicrobial growth promoter factors in poultry. Frontier. Microbiol. 5.

Reeves, P. G., F. H. Nielsen and G. C. Fahey (1993). AIN-93 purified diets for laboratory rodents: Final report of the American Institute of nutrition ad hoc writing committee on the reformulation of the AIN-76A rodent diet. J. Nutr. 123(11): 1939-1951.

Sagae, S.C., E. F. Menezes, M. L. Bonfleur, E. C. Vanzela, P. Zacharias, C. Lubaczeuski, C. R. Franci and G. L. Sanvitto (2012). Early onset of obesity induces reproductive deficits in female rats. Physiol. Behav. 105: 1104-11.

Santos-Buelga, C. and A. Scalbert (2000). Proanthocyanidins and tannin-like compounds nature, occurrence, dietary intake and effects on nutrition and health. J. Sci. Food. Agri. 80(7): 1094-1117.

Schiavone, A., K. Guo, S. Tassone, L. Gasco, E. Hernandez, R. Denti and I. Zoccarato (2008). Effects of a Natural Extract of Chestnut Wood on Digestibility, Performance Traits, and Nitrogen Balance of Broiler Chick. Poult. Sci. 87(3): 521-527.

Shah, D. K., S. A. Missmer, K. F. Berry, C. Racowsky and E. S. Ginsburg (2011). Effect of obesity on oocyte and embryo quality in women undergoing in vitro fertilization. Obst. Gynecol. 118(1): 63-70.

Shi, H., S. Li, Z. Cao, Y. Wang, G. Alugongo and P. Doane (2015). Effects of replacing wild rye, corn silage, or corn grain with $\mathrm{CaO}$-treated corn stover and dried distillers grains with solubles in lactating cow diets on performance, digestibility, and profitability. J. Dairy. Sci. 98(10): 7183-7193.

Silverman, J., M. A. Suckow and S. Murthy (2014). The IACUC Hand Book. $3^{\text {rd }} \mathrm{Ed}$. 
Slaoui, M. and L. Fiette (2010). Histopathology Procedures: From Tissue Sampling to Histopathological Evaluation. Method. Molecul. Biol. 69-82.

Sohrabi, M., A. Mohammadi Roushandeh, Z. Alizadeh, A. Vahidinia, M. Vahabian and M. Hosseini (2015). Effect of a high fat diet on ovary morphology, in vitro development, in vitro fertilisation rate and oocyte quality in mice. Sing. Medi. J. 56(10):573-579.

Spencer, J. P., M. Manal, Abd El Mohsen, A. M. Minihane and J. C. Mathers (2007). Biomarkers of the intake of dietary polyphenols: strengths, limitations and application in nutrition research. Brit. J. Nutr. 99(1):12-22.

Tilly, J. L. and K. I. Tilly (1995). Inhibitors of oxidative stress mimic the ability of follicle-stimulating hormone to suppress apoptosis in cultured rat ovarian follicles. Endocrinol. 136(1): 242-252.
Waghorn, G. C., I . D. Shelton and W. C. McNabb (1994). Effects of condensed tannins in Lotus pedunculatus on its nutritive value for sheep 1 . Non-nitrogenous aspects. J. Agri. Sci 123(1): 99-107.

Wang, N., L. Luo, J. Xu, M. Xu, X. Zhang, X. Zhou and Y. Fu (2014). Obesity accelerates ovarian follicle development and follicle loss in rats. Metabol. 63(1):94-103.

Wang, Y., T. A. McAllister, Z. J. Xu, M. Y. Gruber, B. Skadhauge, B. Jende-Strid and K. Cheng (1999). Effects of proanthocyanidins, dehulling and removal of pericarp on digestion of barley grain by ruminal micro-organisms. J. Sci. Food. Agri. 79(6):929-938.

Yoshida, M., A . Mukama, R. Hosomi, K. Fukunaga and T. Nishiyama (2017). Soybean Meal Reduces Tissue Iodine Concentration in Rats Administered Kombu. J. Biomed. Res. Trac. Elemet. 28 (1): 28-34. 